\title{
Determinants of knowledge regarding folic acid in periconceptional use among pregnant mothers in Southern India
}

\author{
Dr.Kurian Deepti ${ }^{1}$, Dr. Harrison Anila ${ }^{1}$, Dr.Chakraborty Arup ${ }^{2}$, Dr. Balraj \\ Vinohar ${ }^{3}$ \\ ${ }^{1,2,3}$ (Department Of Community Health, Christian Medical College, Vellore, India)
}

\begin{abstract}
Periconceptional supplementation with folic acid has been shown to decrease the occurrence of neural tube defects (anencephaly, encephalocele and spina bifida). Earlier studies, conducted worldwide to assess patient's knowledge regarding periconceptional use of folic acid showed that the overall knowledge about its use among pregnant mothers was low.

A cross-sectional study was conducted to assess the level of knowledge regarding periconceptional use of folic acid and to determine factors influencing knowledge about folic acid among pregnant women. In the sample studied, $36.6 \%$ of study population had heard about folic acid and among them $33.3 \%$ could correctly state the effect of folic acid when used periconceptionally. Among those who had heard about folic acid, $80 \%$ believed that it should be taken only after confirmation of pregnancy. Low levels of education was associated with less knowledge regarding folic acid, and the difference was statistically significant (OR 4.86, 95\% CI 1.74-13.61). Low socio economic status was also significantly associated with poor knowledge (OR 2.371, 95\% CI 1.115.05).The overall knowledge regarding periconceptional use of folic acid among a rural study population was poor. Health education regarding periconceptional use of folic acid among newly married couples may improve knowledge and hence its acceptance in the prevention of neural tube defects. Qualitative assessment regarding knowledge and beliefs also revealed the misconception about role of folic acid and food items containing folic acid among the study population.
\end{abstract}

Keywords: Folic acid, knowledge, pregnant mothers, periconceptional use

\section{Introduction}

Folate is an essential and naturally occurring B vitamin. Synthetic forms of folate, folic acid is more bioavailable and stabler than the natural forms. Apart from green leafy vegetables meat, liver, dairy products and egg are good dietary sources of folic acid. Folic acid deficiency in general population causes megaloblastic anemia. The Indian Council of Medical Research (ICMR) recommends the daily intake of folic acid during pregnancy is $500 \mathrm{mcg}$.[1] According to Government of India programme guideline there is provision for supply of iron and folic acid tablets to each of the antenatal mother. The iron is for maintaining adequate hemoglobin of mother, where as folic acid primarily for the benefit of the fetus. There is increasing evidence that maternal folate deficiency may be a factor in the causation of congenital defects of the neural tube (anencephaly, encephalocele and spina bifida). Periconceptional supplementation of folic acid has been shown to decrease the occurrence of neural tube defects (NTDs), apart from preventing anaemia in human being. The same findings have also been shown in the animal model.[2] The outcome of a non-randomized trial showed that NTD recurrence was high among infants/fetuses examined in the unsupplemented high-risk group, but the recurrence was low among high-risk group receiving full supplementation[3]. As an additional benefit, folic acid supplementation during pregnancy has been found to increase the birth weight of infants and decrease the incidence of low birth weight babies[1]. Although there has been a declining trend in neural tube defects (NTD), the prevalence in Quebec in 1992 was 1.41 per 1000 live births[4].

Many studies have been conducted throughout the world to assess the knowledge regarding periconceptional use of folic acid among different populations. Most of these showed there was a lack of knowledge about folic acid and its uses. This lack of knowledge was dependent on place of treatment (public/private), ethnicity, socioeconomic background, educational status and previous history of fetal demise [5,6]. In Australia, although $62.3 \%$ of women were aware of the correct message regarding intake of folic acid before pregnancy, only $28.5 \%$ reported taking adequate folic acid from supplements each day in the periconceptional period[7]. Awareness about periconceptional folic acid and its benefit was very low (8.7\%) among women of United Arab Emirates and its use was even less.[8]. A study among young women in North Carolina showed poor awareness about importance of folic acid. They were not taking multivitamins containing folic acid, and were not consuming adequate folates in their diets. There were no relationship between pregnancy intention and folic acid intake[9]. In Iran, more than half of study pregnant women were aware that folic acid was beneficial for the fetus, although only $15.4 \%$ knew it could prevent NTDs. Only a fourth who 
used folic acid believed it was most useful when taken preconception ally[10]. In another Arabian community settled in Israel where consanguinity is high, folic acid awareness among the pregnant mother was also low (only 14\% were familiar with the protective effect of NTD). The higher knowledge level was associated with higher education, women with one or two children, paramedics and high socioeconomic status[11]. The levels of folic acid awareness, knowledge and use among Chinese women during pregnancy, living in a high NTD prevalence area was very low and folate deficiency was high. The lower level of knowledge was associated with less education, among farmers, rural dwellers, and women who had a previous child[12]. Among Thai pregnant woman, some were aware of the need to take folic acid, but only few knew that folate was something important. The study also demonstrated education of mother was the strongest predictor of having taken folic acid during the correct period[13]. Trend regarding folic Acid awareness and behavior in the United States in past 10 years (1995-2005) was steadily increased[14]

This study was conducted to assess the level of knowledge regarding periconceptional use of folic acid and to determine factors influencing knowledge about folic acid among pregnant women in primary care.

\section{Methodology}

A cross-sectional study was done among pregnant women attending mobile outreach clinics in selected villages of a rural block in southern India. One of the Medical College in southern India carries out its Community Health and Development (CHAD) programme to provide primary health care through mobile clinics, with a team of doctors, nurses and community based health workers. Five mobile clinics out of eight (during the period $1^{\text {st }}-31^{\text {st }}$ July, 2011) were chosen for the study by simple random sampling. All the ante natal mothers who came to the mobile clinic on that day were included in the study. A structured pretested questionnaire regarding the knowledge about the role of folic acid in periconceptional use was administered to the mothers after obtaining informed consent. Respondent was asked regarding they have ever heard the name and the benefit of folic acid, the source of information, content of the tablet supplied from the health facility, food items that contains folic acid, if they were advised to take folic acid before pregnancy and the source of advice, whether they had taken folic acid before or during their current pregnancy. Demographic, social and obstetric variables taken into consideration were age, education, occupation, family income, obstetric score, current gestational age, number of visit to the health facility, any obstetric risk factor present or not. A score was given to each knowledge based question and a total knowledge score was calculated for each individual. Equal weight age was given to all the questions. The highest score was 6 and lowest was 0 . Subjects were divided into those who did and did not have knowledge based on the median knowledge score which was ' 0 '.

Statistical analysis was done using SPSS version 15[15]. Bivariate analysis was done to find out the association between the knowledge score and various factors like age, obstetric score, obstetric risk factors, gestational age, number of visit to the health facility, education and occupation of subjects, socio economic standards.

Qualitative assessment regarding knowledge and beliefs was done through focus group discussion, conducted among pregnant mothers in three villages, with 9 to 13 participant mothers in each group.

\section{Results}

A total of 131 mothers had been interviewed. There were no refusals. The mean age of study population was 23.64 years (range, 18-35 years; SD 3.57 years), 22.9\% had consanguineous marriage, $60 \%$ were primigravida, a third had visited the mobile clinic for the first time on the day of the study. The median level of education of the study population was high school level $\left(12^{\text {th }}\right.$ standard $)$ and $3.8 \%$ were illiterate, $85 \%$ were unemployed at the time of the interview, 93\% belonged to upper middle and upper socio economic category. The demographic characteristics of the study population shown in "Table 1".

Only 48/131 (36.6\%) study subjects heard about folic acid. Among those who had heard, $45.8 \%$ got the information from that Community health and development( CHAD) programme; $18.7 \%$ had information from Government health care providers and $35.4 \%$ got the information from other sources. Though only $21 / 131(16 \%)$ of them received the message to take folic acid before conception but only $5 / 131(3.8 \%)$ did so.("Table 2")

Eighty three (63.4\%) did not get any knowledge score, the lowest score was 0 and the maximum was 6 ("Table 3"). Mothers with less education had poorer knowledge (OR 4.868, 95\% CI 1.74-13.61), mothers in lower socio-economic group had poorer knowledge about folic acid (OR 2.371, 95\% CI 1.11-5.05). Previous bad obstetric history did not influence knowledge score of the pregnant mother (OR 1.875, 95\% 0.65-5.37). The study did not find a statistical association between level of knowledge and age, obstetric score, duration of gestational period, number of ante natal visits to the mobile clinic or occupation of the subjects ("Table 4").

Focus group discussions among pregnant mother in that community revealed that there was misconception and misbelieve regarding food items during pregnancy and the relationship between folic acid and the "baby's back bone and spinal cord" was largely unknown. 


\section{Discussion}

This study aimed to identify current levels of knowledge regarding periconceptional use of folic acid among pregnant women and to determine factors influencing that knowledge.

It was found that the overall knowledge regarding folic acid in this study population was poor. Similar finding had been observed in different studies worldwide in developing as well as developed countries. The level of knowledge was poor among the pregnant mothers and postpartum women of United Arab Emirates, Chinese, Thailand and Japan. $[8,12,13,16]$.

The study also revealed that mothers who were less educated had a poorer knowledge than others. Lower education may be a barrier in being able to come across key messages regarding folic acid either because of the forums where it is discussed or the content, both of which may not reach sections of society with lower levels of education. In North China where the prevalence of NTDs is high, knowledge was found low among the less educated women [12]. In Thailand education found the strongest predictor for acquiring knowledge about folic acid[13] and in Texas and Michigan, two different studies showed poor knowledge was associated with the poor educational status among women in child bearing age[5,17].

Lower socio economic status also was associated with poorer knowledge both in this study as well as in other countries[11,17] and is perhaps linked to lower levels of education among such groups.

Like other studies this study also did not find any association between level of knowledge and age, obstetric score, duration of gestational period, number of ante natal visits[11]

While one assumes that subjects who had a previous bad pregnancy outcome would have better knowledge about folic acid, this study did not reveal any such association. Similar findings were observed in Texas among the pregnant mother with previous bad child birth outcome[6].

Health education among the women of child bearing age can improve the knowledge. Studies have suggested on greater emphasis for strategies to improve the levels of folic acid knowledge and folic acid supplementation for those with poor knowledge[5]. Pre and post health education level of awareness regarding folic acid in Netherland showed marked improvement of knowledge after health education[18].

\section{Conclusion}

This study revealed overall knowledge regarding periconceptional use of folic acid among a rural study population in Southern India was poor. A significant difference between poor knowledge and lower level of education of the pregnant mother and low socio economic status were identified. Health education regarding periconceptional use of folic acid among newly married couples and women in child bearing age group may improve knowledge and hence its acceptance in the prevention of neural tube defects. Supplementation is a strategy for specific groups among those with poor knowledge and lower socioeconomic standards.

\section{Acknowledgement}

Books :

\section{References}

[1]. K.Park. Preventive and social medicine ( 21 st ed. Bhanot; 2011.)

\section{Journal Papers:}

[2]. Seller MJ. An essay on research into the causation and prevention of spina bifida. Z Kinderchir. 1981 Dec;34(4):306-14.

[3]. Schorah CJ, Wild J, Hartley R, Sheppard S, Smithells RW. The effect of periconceptional supplementation on blood vitamin concentrations in women at recurrence risk for neural tube defect. Br. J. Nutr. 1983 Mar;49(2):203-11.

[4]. De Wals P, Trochet C, Pinsonneault L. Prevalence of neural tube defects in the province of Quebec, 1992. Can J Public Health. 1999 Aug;90(4):237-9.

[5]. Canfield MA, Przybyla SM, Case AP, Ramadhani T, Suarez L, Dyer J. Folic acid awareness and supplementation among Texas women of childbearing age. Prev Med. 2006 Jul;43(1):27-30.

[6]. Canfield MA, Anderson JL, Waller DK, Palmer SE, Kaye CI. Folic acid awareness and use among women with a history of a neural tube defect pregnancy--Texas, 2000-2001. MMWR Recomm Rep. 2002 Sep 13;51(RR-13):16-9.

[7]. Bower C, Miller M, Payne J, Serna P. Promotion of folate for the prevention of neural tube defects: who benefits? Paediatr Perinat Epidemiol. 2005 Nov;19(6):435-44.

[8]. Abdulrazzaq YM, Al-Gazali LI, Bener A, Hossein M, Verghese M, Dawodu A, et al. Folic acid awareness and intake survey in the United Arab Emirates. Reprod. Toxicol. 2003 Apr;17(2):171-6.

[9]. Hilton JJ. A comparison of folic acid awareness and intake among young women aged 18-24 years. J Am Acad Nurse Pract. 2007 Oct;19(10):516-22.

[10]. Simin Ozar MASHAYEKHI PhD1. A survey on the consumption, knowledge and attitudeof pregnant women toward the efects of folic acid onpregnancy outcome in Tabriz. Iran J Child Neurology. 2011;Vol 5(No1 Winter):35-42.

[11]. Jaber L, Karim IA, Jawdat AM, Fausi M, Merlob P. Awareness of folic acid for prevention of neural tube defects in a community with high prevalence of consanguineous marriages. Ann. Genet. 2004 Mar;47(1):69-75.

[12]. Ren A, Zhang L, Li Z, Hao L, Tian Y, Li Z. Awareness and use of folic acid, and blood folate concentrations among pregnant women in northern China--an area with a high prevalence of neural tube defects. Reprod. Toxicol. 2006 Oct;22(3):431-6.

[13]. Nawapun K, Phupong V. Awareness of the benefits of folic acid and prevalence of the use of folic acid supplements to prevent neural tube defects among Thai women. Arch. Gynecol. Obstet. 2007 Jul;276(1):53-7. 
[14]. Green-Raleigh K, Carter H, Mulinare J, Prue C, Petrini J. Trends in folic Acid awareness and behavior in the United States: the Gallup Organization for the March of Dimes Foundation surveys, 1995-2005. Matern Child Health J. 2006 Sep;10(5 Suppl):S177-82.

Chapters in Books :

[15]. Daniel Wayne. Biostatistics, A foundation for analysis in the health science (7th ed. Wiley India; 2005). 618-625

\section{Journal Papers:}

[16]. Kondo A, Kamihira O, Shimosuka Y, Okai I, Gotoh M, Ozawa H. Awareness of the role of folic acid, dietary folate intake and plasma folate concentration in Japan. J. Obstet. Gynaecol. Res. 2005 Apr;31(2):172-7.

[17]. Alozie Arole CN, Puder KS, Reznar M, Eby E, Zhu B-P. Folic acid awareness in Michigan, 1996-1999. Obstet Gynecol. 2003 Nov; 102(5 Pt 1):1046-50.

[18]. de Jong-van den Berg LT, de Walle HE, van der Pal-de Bruin KM, Buitendijk SE, Cornel MC. Increasing awareness of and behaviour towards periconceptional folic acid consumption in The Netherlands from 1994 to 1995. Eur. J. Clin. Pharmacol. 1998 Jun;54(4):329-31.

Table 1. Socio-demographic characteristics of the study population $(\mathrm{N}=131)$

\begin{tabular}{|l|l|l|l|}
\hline 1. & Age & $\begin{array}{l}<=20 \text { years } \\
21-24 \text { years } \\
>=25 \text { years }\end{array}$ & $\begin{array}{l}25(19.1 \%) \\
59(45 \%) \\
47(35.9 \%)\end{array}$ \\
\hline 2. & & Absent & $115(87.8 \%)$ \\
& Obstetric risk factors & $\begin{array}{l}\text { Primi gravida } \\
2^{\text {nd }} \text { gravida }\end{array}$ & $16.2 \%)$ \\
\hline \hline 3. & Obstetric score & $3^{\text {rd }}$ gravida and more & $79(60.3 \%)$ \\
& & Up to 3 visit & $34(26 \%)$ \\
& & More than 3 visit & $18(13.7 \%)$ \\
\hline 4. & Number of visits & Illiterate & $95(72.5 \%)$ \\
& & Upto 12 & $36(27.5 \%)$ \\
\hline 5. & Education status & Above $12^{\text {th }}$ standard & $5(3.8 \%)$ \\
& & Unemployed & $80(61.1 \%)$ \\
& & Employed & $46(35.1 \%)$ \\
\hline 6. & Occupation status & Upper lower & $112(85.8 \%)$ \\
& & Lower middle & $19(14.5 \%)$ \\
\hline \hline 7. & Socioeconomic status & Upper middle & $2(1.5 \%)$ \\
& & Upper & $7(5.3 \%)$ \\
& & & $109(83.2 \%)$ \\
& & & $13(9.9 \%)$ \\
\hline
\end{tabular}

Table 2. Knowledge related informations among the study population $(\mathrm{N}=131)$

\begin{tabular}{|l|l|}
\hline Subjects heard about folic acid & $48(36.6 \%)$ \\
\hline $\begin{array}{l}\text { Subjects correctly knew regarding benefit of folic } \\
\text { acid }\end{array}$ & $16(12.2 \%)$ \\
\hline $\begin{array}{l}\text { Subjects correctly knew the food items containing } \\
\text { folic acid }\end{array}$ & $40(30.5 \%)$ \\
\hline $\begin{array}{l}\text { Subjects correctly knew about the content of the } \\
\text { tablet }\end{array}$ & $22(16.7 \%)$ \\
\hline $\begin{array}{l}\text { Subjects received advice from the health care } \\
\text { provider regarding periconceptional use of folic acid }\end{array}$ & $21(16.0 \%)$ \\
\hline Subjects took folic acid before conception & $5(3.8 \%)$ \\
\hline
\end{tabular}

Table 3.Frequency of Knowledge score $(\mathrm{N}=131)$.

\begin{tabular}{|l|l|}
\hline Score & Number $(\%)$ \\
\hline 0 & $83(63.4)$ \\
\hline 1 & $3(2.29)$ \\
\hline 2 & $20(15.26)$ \\
\hline 3 & $1(0.76)$ \\
\hline 4 & $14(10.68)$ \\
\hline 5 & $1(0.76)$ \\
\hline 6 & $9(6.87)$ \\
\hline
\end{tabular}


Table 4. Knowledge score and associated potential risk factors

\begin{tabular}{|c|c|c|c|c|c|}
\hline $\begin{array}{l}\text { Name of the risk } \\
\text { factors }\end{array}$ & $\begin{array}{l}\text { Description of } \\
\text { risk factors }\end{array}$ & $\begin{array}{l}\text { Number with no } \\
\text { knowledge group }\end{array}$ & $\begin{array}{l}\text { Number with } \\
\text { some knowledge } \\
\text { group }\end{array}$ & p-value & OR $(95 \% \mathrm{CI})$ \\
\hline Age & $\begin{array}{l}<23 \text { years } \\
>23 \text { years }\end{array}$ & $\begin{array}{l}40 \\
43\end{array}$ & $\begin{array}{l}19 \\
29\end{array}$ & 0.340 & $\begin{array}{l}1.420(0.690- \\
2.920)\end{array}$ \\
\hline Obstetric score & $\begin{array}{l}\text { Primigraxida } \\
\text { Multigravida }\end{array}$ & $\begin{array}{l}50 \\
33 \\
\end{array}$ & $\begin{array}{l}29 \\
19 \\
\end{array}$ & 0.948 & $\begin{array}{l}0.993(.480- \\
2.053)\end{array}$ \\
\hline $\begin{array}{l}\text { Obstetric risk } \\
\text { factor }\end{array}$ & $\begin{array}{l}\text { Absent } \\
\text { Present }\end{array}$ & $\begin{array}{l}75 \\
8 \\
\end{array}$ & $\begin{array}{l}40 \\
8\end{array}$ & 0.237 & $\begin{array}{l}1.875(.655- \\
5.371)\end{array}$ \\
\hline Gestational age & $\begin{array}{l}<28 \text { weeks } \\
>28 \text { weeks }\end{array}$ & $\begin{array}{l}45 \\
38\end{array}$ & $\begin{array}{l}24 \\
24\end{array}$ & 0.641 & $1.184(0.58-2.41)$ \\
\hline Number of visit & $\begin{array}{l}<2 \text { visits } \\
>2 \text { visit }\end{array}$ & $\begin{array}{l}29 \\
54\end{array}$ & $\begin{array}{l}14 \\
34\end{array}$ & 0.498 & $1.304(0.60-2.81)$ \\
\hline $\begin{array}{l}\text { Education of } \\
\text { subject }\end{array}$ & $\begin{array}{l}<12^{\text {th }} \text { standard } \\
>12^{\text {th }} \text { standard }\end{array}$ & $\begin{array}{l}30 \\
53\end{array}$ & $\begin{array}{l}5 \\
43 \\
\end{array}$ & 0.001 & $\begin{array}{l}4.868(1.74- \\
13.61)\end{array}$ \\
\hline $\begin{array}{l}\text { Occupation of } \\
\text { subject }\end{array}$ & $\begin{array}{l}\text { Unemployed } \\
\text { Employed }\end{array}$ & $\begin{array}{l}70 \\
13\end{array}$ & $\begin{array}{l}42 \\
6\end{array}$ & 0.620 & $0.769(.27-2.17)$ \\
\hline $\begin{array}{l}\text { Socioeconomic } \\
\text { standards }\end{array}$ & $\begin{array}{l}\text { Lower } \\
\text { Higher }\end{array}$ & $\begin{array}{l}41 \\
42\end{array}$ & $\begin{array}{l}14 \\
34\end{array}$ & 0.024 & $2.371(1.11-5.05)$ \\
\hline
\end{tabular}

